\title{
Hot Drawing of Ultrahigh Molecular Weight Polyethylene
}

\author{
Akira KaITo, Kazuo NAKAYAMA, and Hisaaki KANETSUNA \\ Research Institute for Polymers and Textiles, \\ 1-1-4, Yatabe-Higashi, Tsukuba, Ibaraki 305, Japan
}

(Received December 22, 1981)

\begin{abstract}
Uniaxial drawing of ultrahigh molecular weight polyethylene (UHMW-PE) sheets was carried out both in the solid and molten states over a temperature range from $120^{\circ} \mathrm{C}$ to $150^{\circ} \mathrm{C}$. For two UHMW-PE samples of higher molecular weight, melt drawing yielded higher Young's moduli than solid drawing. The molecular orientation, the microstructure, and the melting behavior of hot drawn UHMW-PE sheets were investigated by wide angle X-ray diffraction (WAXD), small angle X-ray scattering (SAXS), differential scanning calorimetry (DSC), density, and birefringence. The hot drawn UHMW-PE sheets were found to be distinctly different from hot drawn normal molecular weight high density polyethylene (NMW-HDPE) sheets with respect to SAXS pattern, melting behavior, and crystallinity.

KEY WORDS Polyethylene / Ultrahigh Molecular Weight / Drawing / Stretching / Mechanical Properties / Molecular Orientation / Microstructure / Melting Behavior /
\end{abstract}

In spite of its poor processibility, ultrahigh molecular weight polyethylene (UHMW-PE) has attracted interest of many investigators, ${ }^{1,2)}$ because of its superiority in physical properties such as toughness, abrasion resistance, self lubrication, moisture absorption, and chemical innertness, over normal molecular weight high density polyethylene (NMWHDPE). Young's moduli as high as $60-120 \mathrm{GPa}$ were obtained by hot drawing NMW-HDPE sheets, ${ }^{3-6}$ melt spun NMW-HDPE fibers, ${ }^{7}$ and solution spun UHMW-PE ${ }^{8-11}$ to high draw ratios $(\lambda=20-40)$. However, melt crystallized UHMWPE could not be extended to such a high draw ratio even at elevated temperatures. ${ }^{12-15}$ UHMW-PE was hydrostatically extruded to an extrusion ratio of 5.3, but this ratio was far less than the extrusion limit for NMW-HDPE. ${ }^{12}$ Solid state coextrusion and compacted powder extrusion techniques were applied to UHMW-PE. ${ }^{13,14}$ The extrudate from compacted powder of UHMW-PE showed a modulus as high as $15 \mathrm{GPa}$ but a tensile strength as low as $0.11 \mathrm{GPa} .{ }^{13,14}$ Capaccio et al. ${ }^{15}$ reported that Young's modulus of $7 \mathrm{GPa}$ was obtained by hot drawing UHMW-PE to $\lambda=17$ at $135^{\circ} \mathrm{C}$.

Sakami et al. ${ }^{16-18}$ investigated the morphology of an UHMW-PE film crystallized under uniaxial and biaxial drawing above its melting temperature by means of scanning electron microscopy, DSC, and X-ray diffraction. Oriented fibrils containing orthorohmbic extended chain crystals were produced by drawing at temperatures above the melting point. ${ }^{16-18}$

In this work, we investigated the effects of draw ratio, drawing temperature, and molecular weight on mechanical properties, molecular orientation, and microstructure of UHMW-PE sheets drawn both in the solid and molten states.

\section{EXPERIMENTAL}

\section{Sample Preparation}

The samples used in this work were three different grades of UHMW-PE, Hizex Million (Mitsui Petrochemical Co., Ltd.). Their molecular weights and melting points are summarized in Table $\mathbf{I}$. Polymer sheets $0.5-0.8 \mathrm{~mm}$ thick were obtained by compression moulding the powder of UHMW-PE at $220-250^{\circ} \mathrm{C}$ under a pressure of $6-7 \mathrm{MPa}$.

Samples with gauge dimensions of $2 \times 2 \mathrm{~cm}^{2}$ were cut from the sheets and drawn uniaxially in an oven using a hand operated drawing apparatus. Drawing in the melt state was carried out in the temperature 
Table I. UHMW-PE used in this work

\begin{tabular}{crrrr}
\hline Grade & $M_{v}{ }^{\mathrm{a}}$ & $\frac{T_{\mathrm{m}}{ }^{\mathrm{a}, \mathrm{b}}}{}$ & & ${ }^{T_{\mathrm{mp}}{ }^{\mathrm{c}}}$ \\
\cline { 5 - 5 } \cline { 5 - 5 } & & ${ }^{\circ} \mathrm{C}$ & & ${ }^{\circ} \mathrm{C}$ \\
\hline Hizex Million 145 M & 700000 & & & 131.6 \\
Hizex Million 240 M & 1900000 & 136 & & 131.1 \\
Hizex Million 340 M & 2700000 & 136 & & 132.0 \\
\hline
\end{tabular}

a Supplyer's data.

b $T_{\mathrm{m}}$, melting temperature determined by visual observation with a polarizing microscope.

c $T_{\mathrm{mp}}$, peak melting temperature on the DSC curve.

range from 136 to $150^{\circ} \mathrm{C}$ (above $T_{\mathrm{m}}$ in Table I), after the polymer sheets were melted at $140-160^{\circ} \mathrm{C}$.

\section{Characterization of Samples}

Tensile properties were measured at $23 \pm 1^{\circ} \mathrm{C}$ and a relative humidity of $50 \pm 2 \%$ on a tensile testing machine, Tensilon UTM-III-100 (Toyo Baldwin Co., Ltd.), using a $16 \mathrm{~mm}$ gauge length and a $4 \mathrm{~mm}$ $\min ^{-1}$ tensile rate. Young's modulus was determined from the slope of the stress-strain curve below $1 \%$ strain.

Wide angle X-ray diffraction (WAXD) patterns were taken with a plate camera. Ni-filtered $\mathrm{Cu}-K \alpha$ radiation $(40 \mathrm{kV}, 25 \mathrm{~mA})$ produced by a Geiger Flex XGC-20 (Rigaku Denki Co., Ltd.) was used. The WAXD intensity profiles were measured using a scintillation counter along with a pulse height analyzer.

Crystallite size was calculated from the integrated WAXD line width using the Scherrer equation, ${ }^{19}$ after correction for instrumental and $K \alpha$ doublet broadenings was made by the Jones method. ${ }^{20}$

The degree of orientation of the crystal axis was estimated from WAXD azimuthal scanning data for (200) and (020) reflections, using the Hermans-type orientation function. ${ }^{21}$

Small angle X-ray scattering (SAXS) patterns were taken with a vacuum camera. Ni-filtered $\mathrm{Cu}$ $K \alpha$ radiation $(40 \mathrm{kV}, 100 \mathrm{~mA})$ produced by a Rota Flex RU-200 (Rigaku Denki Co., Ltd.) and pinhole collimators with $0.2-0.5 \mathrm{~mm}$ diameter were used. In order to evaluate the periodicity, the intensity distribution of the SAXS was measured with a scintillation counter.

Sample melting behavior was examined at a constant heating rate of $5^{\circ} \mathrm{C} \mathrm{min}{ }^{-1}$ using a Perkin

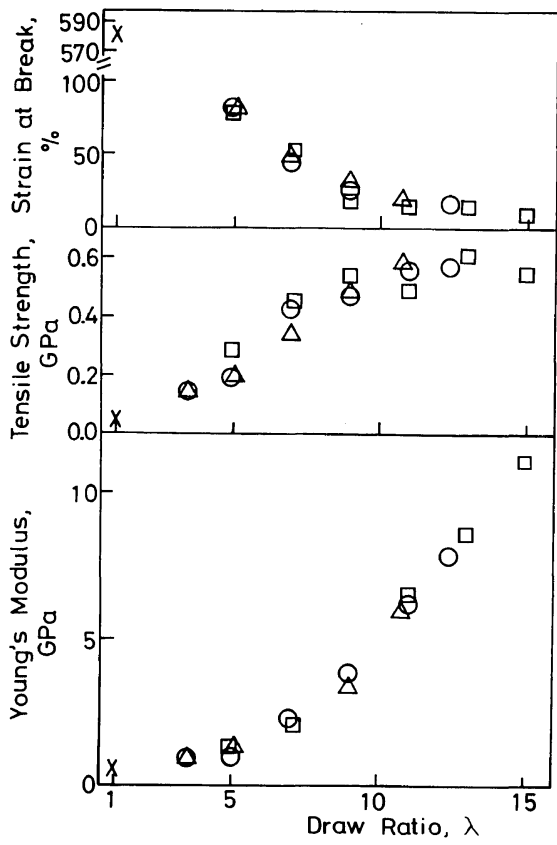

Figure 1. Tensile properties vs. draw ratio ralationship for solid drawn $145 \mathrm{M}$ sheets. Drawing temperatures: $120^{\circ} \mathrm{C}(\triangle) ; 130^{\circ} \mathrm{C}(\bigcirc) ; 134^{\circ} \mathrm{C}(\square)$.

Elmer DSC-2 differential scanning calorimeter. The temperature was calibrated with standard samples of indium $\left(T_{\mathrm{m}}=156.5^{\circ} \mathrm{C}\right)$ and benzil $\left(T_{\mathrm{m}}=95^{\circ} \mathrm{C}\right)$.

Density was measured using an ethanol-water density gradient column at $25^{\circ} \mathrm{C}$. The degree of crystallinity, i.e., the weight fraction of the crystalline phase, was calculated assuming the densities of the crystalline and amorphous phases to be $0.999 \mathrm{~g}$ $\mathrm{cm}^{-3}$ and $0.8525 \mathrm{~g} \mathrm{~cm}^{-3}$, respectively. ${ }^{22-24}$

Birefringence was measured by the retardation method using a polarized microscope equipped with a Berek compensator. The degree of orientation in the amorphous phase was estimated on the assumption that birefringences of the amorphous and crystalline phases are additive. The values of 0.0572 and 0.0485 were used for the intrinsic birefringences of the completely oriented crystalline and amorphous regions, respectively. ${ }^{25}$

\section{RESULTS}

\section{Appearance}

The uniaxially drawn sheets elastically contracted immediately following the removal of tension. The degree of contraction was negligibly small at high 
Table II. Tensile properties of UHMW-PE sheets drawn to the maximum draw ratio, $\lambda_{\max }$ at each drawing temperature, $T_{\mathrm{d}}$

\begin{tabular}{|c|c|c|c|c|c|c|}
\hline \multirow[t]{2}{*}{ Grade } & \multirow[t]{2}{*}{ State } & \multirow{2}{*}{$\frac{T_{\mathrm{d}}}{{ }^{\circ} \mathrm{C}}$} & \multirow{2}{*}{$\lambda_{\max }$} & \multirow{2}{*}{$\frac{\begin{array}{c}\text { Young's } \\
\text { modulus }\end{array}}{\mathrm{GPa}}$} & \multirow{2}{*}{$\begin{array}{r}\begin{array}{r}\text { Tensile } \\
\text { strength }\end{array} \\
\mathrm{GPa}\end{array}$} & \multirow{2}{*}{$\begin{array}{c}\begin{array}{c}\text { Strain at } \\
\text { break }\end{array} \\
\%\end{array}$} \\
\hline & & & & & & \\
\hline \multirow{3}{*}{$145 \mathrm{M}$} & Solid & 120 & 10.8 & 5.95 & 0.587 & 21.4 \\
\hline & & 130 & 12.4 & 7.91 & 0.571 & 17.4 \\
\hline & & 134 & 15.0 & 11.1 & 0.546 & 9.4 \\
\hline \multirow[t]{2}{*}{$145 \mathrm{M}$} & Melt & 136 & 36.0 & 3.60 & 0.204 & 16.9 \\
\hline & & 140 & 23.6 & 0.95 & 0.047 & 62.3 \\
\hline \multirow[t]{3}{*}{$240 \mathrm{M}$} & Solid & 120 & 7.4 & 1.54 & 0.285 & 31.0 \\
\hline & & 130 & 11.0 & 5.50 & 0.424 & 12.9 \\
\hline & & 134 & 9.0 & 2.54 & 0.376 & 23.1 \\
\hline \multirow[t]{3}{*}{$240 \mathrm{M}$} & Melt & 136 & 21.1 & 13.7 & 0.504 & 6.8 \\
\hline & & 140 & 22.7 & 15.3 & 0.439 & 4.4 \\
\hline & & 150 & 17.9 & 6.54 & 0.315 & 10.7 \\
\hline \multirow[t]{3}{*}{$340 \mathrm{M}$} & Solid & 120 & 6.7 & 1.07 & 0.215 & 34.2 \\
\hline & & 130 & 8.9 & 3.61 & 0.395 & 21.8 \\
\hline & & 134 & 8.4 & 2.05 & 0.317 & 20.8 \\
\hline \multirow[t]{3}{*}{$340 \mathrm{M}$} & Melt & 136 & 12.6 & 7.78 & 0.391 & 6.9 \\
\hline & & 140 & 12.0 & 4.00 & 0.317 & 13.9 \\
\hline & & 150 & 10.1 & 3.67 & 0.252 & 15.4 \\
\hline
\end{tabular}

draw ratios. The solid drawn sheets were transparent and had smooth surfaces, while the melt drawn sheets were opaque or translucent.

\section{Tensile Properties}

Figure 1 shows the tensile properties of the solid drawn $145 \mathrm{M}$ sheets. The tensile strength increased with increasing draw ratio up to $\lambda=9$, and approached a constant value. Young's modulus also increased with draw ratio, quite appreciably above $\lambda=7$. On the other hand, the strain at break decreased rapidly at the initial stage of drawing and gradually decreased with increasing draw ratio.

Table II gives the mechanical properties of the sheets drawn to the highest draw ratios. At a fixed drawing temperature, a higher draw ratio was obtained for a sheet of lower molecular weight. In the case of solid drawing, Young's modulus vs. the draw ratio relationship was hardly affected by molecular weight, and the highest modulus was obtained for the $145 \mathrm{M}$ sheet.

The melt drawing was greatly influenced by molecular weight. Although the $145 \mathrm{M}$ sheet could be drawn to $\lambda=36$ at $136^{\circ} \mathrm{C}$, its Young's modulus and tensile strength were lower than those obtained by solid drawing. The moduli of the $240 \mathrm{M}$ and $340 \mathrm{M}$ sheets obtained by melt drawing were higher than those by solid drawing. The modulus as high as 15 $\mathrm{GPa}$ was obtained when the $240 \mathrm{M}$ sheet was melt drawn to $\lambda=22.7$ at $140^{\circ} \mathrm{C}$.

\section{Wide Angle X-Ray Diffraction}

The WAXD patterns of the $240 \mathrm{M}$ sheets are given in Figure 2. For the solid drawn sheet, the (200) and (020) reflections were sharply concentrated on the equator, suggesting a high uniaxial crystal orientation. Although the (020) reflection of the melt drawn sheet was concentrated on the equator, the (200) reflection consisted of a strong maximum on the equator with a weak ring. The azimuthal scan of the (200) reflection of the melt drawn sheet is presented in Figure 3 which shows two modes of orientation of the a-axis: one highly oriented perpendicularly to the draw direction and another almost randomly oriented.

The degrees of orientation of the a-, b-, and caxes $\left(f_{\mathrm{a}}, f_{\mathrm{b}}\right.$, and $\left.f_{\mathrm{c}}\right)$ and the amorphous chains $\left(f_{\mathrm{am}}\right)$ are shown in Figure 4. For the solid drawn sheet, $f_{\mathrm{c}}$ 


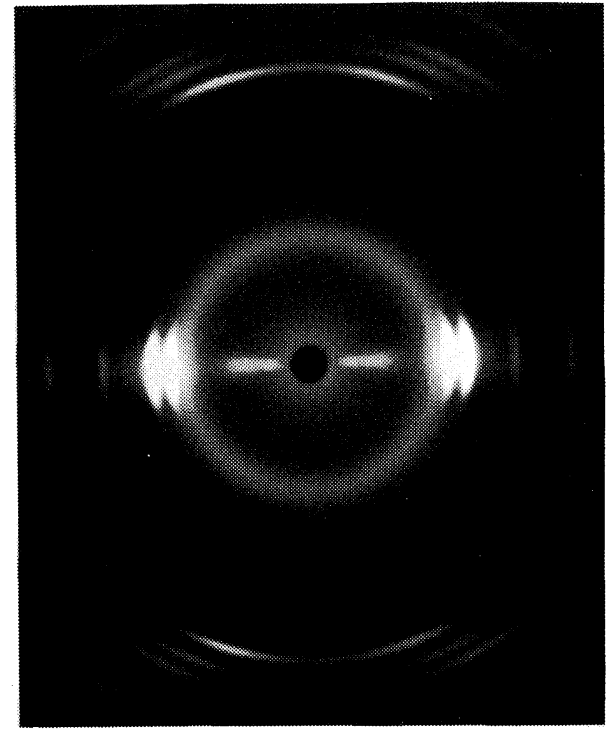

$\lambda 3.5 T_{\mathrm{d}} 130^{\circ} \mathrm{C}$

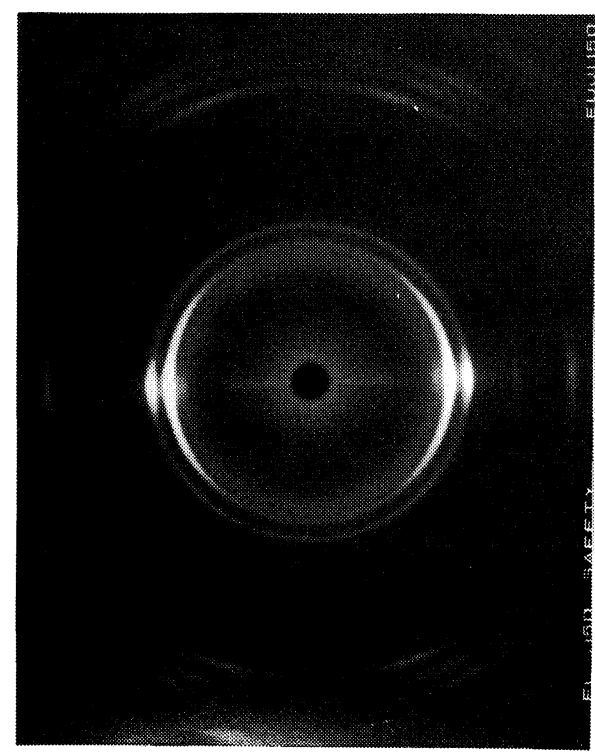

$9.3 \quad 150^{\circ} \mathrm{C}$

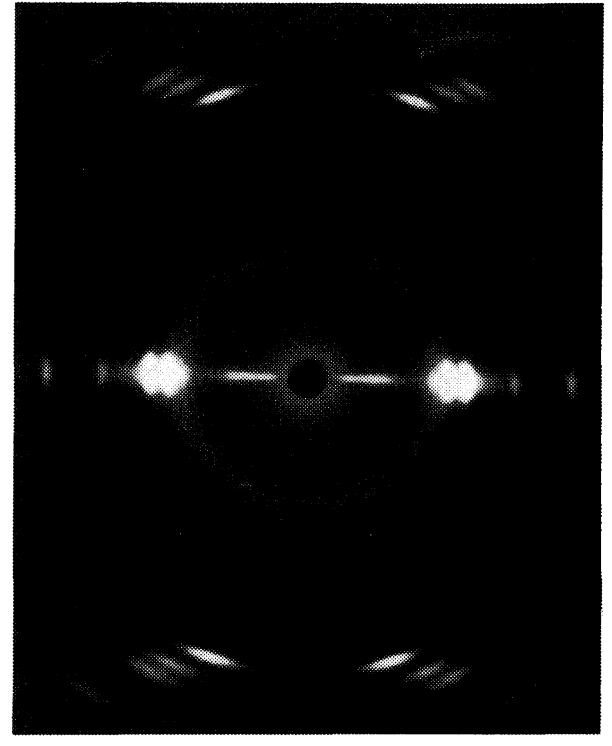

$11 \quad 130^{\circ} \mathrm{C}$

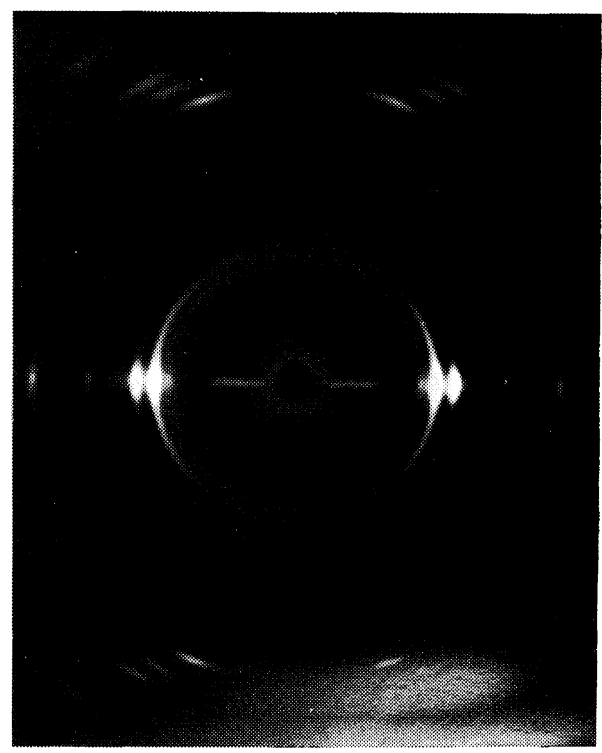

$17.9 \quad 150^{\circ} \mathrm{C}$

Figure 2. Wide angle X-ray diffraction patterns of $240 \mathrm{M}$ sheets. Drawing temperatures $\left(T_{\mathrm{d}}\right): 130^{\circ} \mathrm{C}$, $150^{\circ} \mathrm{C}$; draw ratios $(\lambda)$ : $3.5-17.9$; draw direction is vertical.

reached a maximum at $\lambda=7$, whereas $f_{\text {am }}$ monotonically increased with the draw ratio. The a-axis tended to orient perpendicularly to the draw direction more readily than the b-axis at the initial stage of solid drawing at $120^{\circ} \mathrm{C}$. A similar trend was found in the drawing ${ }^{26}$ and the hydrostatic extrusion $^{27}$ of NMW-HDPE.
For the melt drawn sheet, $f_{\mathrm{a}}$ approached more slowly -0.5 than $f_{\mathrm{b}}$ because of the existence of the almost randomly oriented component.

The crystallite sizes in the $240 \mathrm{M}$ sheets in the direction normal to the (200) and (020) planes, $D_{200}$ and $D_{020}$, are given in Table III. The values of $D_{200}$ and $D_{020}$ for the solid drawn sheet tended to 


\section{Hot Drawing of UHMW-PE}

decrease with increasing draw ratio. The crystallite size in the melt drawn sheet increased as the drawing temperature rose.

\section{Small Angle X-Ray Scattering}

The SAXS patterns of the $240 \mathrm{M}$ sheets are presented in Figure 5. The solid drawn sheet shows a two-layer pattern on the meridian at a low draw ratio $(\lambda=3.5)$ and a four-point pattern at higher draw ratios $(\lambda \geqq 5)$. With increasing draw ratio, the intensity of SAXS decreased. The angle $\phi$ at the intensity maximum measured from the meridian (Figure 5) corresponds to the angle between the direction of periodic layer stacking and the draw direction. The long period $L$ in the direction normal

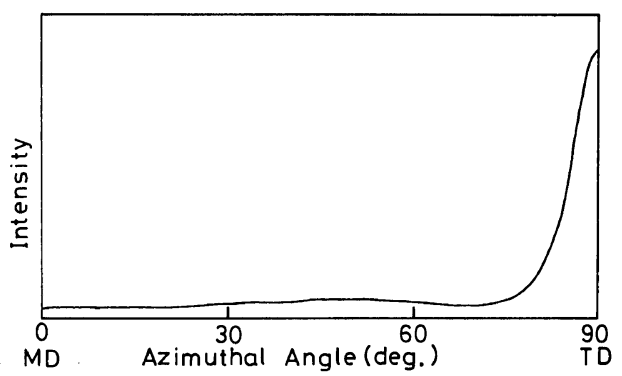

Figure 3. X-ray intensity of the (200) reflection $v s$. azimuthal angle for the $240 \mathrm{M}$ sheet melt drawn to $\lambda=$ 9.3 at $150^{\circ} \mathrm{C}$. to the layers was obtained from the radial intensity distribution at $\phi$. The values of $L$ and $\phi$, summarized in Table III, indicate that with increasing draw ratio, $\phi$ increases and $L$ decreases, but the long period in the draw direction $L / \cos \phi$ scarcely varies with the draw ratio.

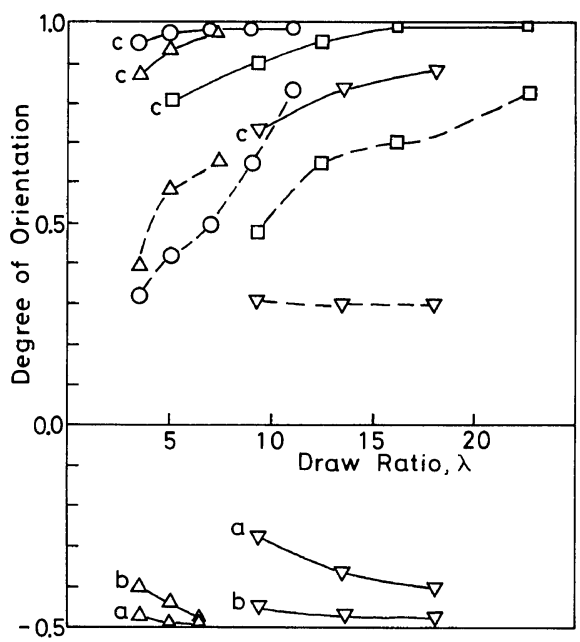

Figure 4. Degree of orientation in crystalline (-) and amorphous (---) regions $v s$. draw ratio for $240 \mathrm{M}$ sheet. Drawing temperatures: $120^{\circ} \mathrm{C}(\triangle) ; 130^{\circ} \mathrm{C}(\mathrm{O})$; $140^{\circ} \mathrm{C}(\square) ; 150^{\circ} \mathrm{C}(\nabla) . \mathrm{a}, \mathrm{b}$, and c stand for the a-, b-, and c-axes, respectively.

Table III. Crystallite size and SAXS data on $240 \mathrm{M}$ sheets

\begin{tabular}{|c|c|c|c|c|c|c|c|}
\hline State & $\frac{T_{\mathrm{d}}}{{ }^{\circ} \mathrm{C}}$ & $\lambda$ & $\frac{D_{200}}{\mathrm{~nm}}$ & $\frac{D_{020}}{\mathrm{~nm}}$ & $\frac{L}{\mathrm{~nm}}$ & $\frac{\phi}{\circ}$ & $\frac{L / \cos \phi}{\mathrm{nm}}$ \\
\hline Solid & 120 & $\begin{array}{l}3.5 \\
5.0 \\
7.4\end{array}$ & $\begin{array}{r}10.9 \\
10.1 \\
9.3\end{array}$ & $\begin{array}{l}11.1 \\
10.8 \\
10.9\end{array}$ & $\begin{array}{l}44 \\
27 \\
22\end{array}$ & $\begin{array}{r}0 \\
63 \\
65\end{array}$ & $\begin{array}{l}44 \\
59 \\
52\end{array}$ \\
\hline Solid & 130 & $\begin{array}{r}3.5 \\
5.0 \\
7.0 \\
11.0\end{array}$ & $\begin{array}{r}10.7 \\
10.2 \\
9.0 \\
9.2\end{array}$ & $\begin{array}{r}11.3 \\
11.4 \\
9.8\end{array}$ & $\begin{array}{r}32 \\
29 \\
26 \\
\text { a }\end{array}$ & $\begin{array}{l}59 \\
63 \\
64 \\
67\end{array}$ & $\begin{array}{l}61 \\
63 \\
59\end{array}$ \\
\hline Melt & 140 & $\begin{array}{r}9.3 \\
12.4 \\
16.1 \\
22.7\end{array}$ & $\begin{array}{l}11.1 \\
11.9 \\
11.1 \\
10.2\end{array}$ & $\begin{array}{l}12.6 \\
13.4 \\
12.2 \\
11.7\end{array}$ & $\begin{array}{r}59 \\
55 \\
\mathrm{a} \\
\mathrm{a}\end{array}$ & $\begin{array}{l}0 \\
0 \\
0 \\
0\end{array}$ & $\begin{array}{l}59 \\
55\end{array}$ \\
\hline Melt & 150 & $\begin{array}{r}9.3 \\
13.4 \\
17.9\end{array}$ & $\begin{array}{l}13.1 \\
12.3 \\
12.4\end{array}$ & $\begin{array}{l}14.2 \\
13.8 \\
12.1\end{array}$ & $\begin{array}{l}52 \\
52 \\
49\end{array}$ & $\begin{array}{l}0 \\
0 \\
0\end{array}$ & $\begin{array}{l}52 \\
52 \\
49\end{array}$ \\
\hline
\end{tabular}

a SAXS intensity was too weak to allow determination of the long period. 


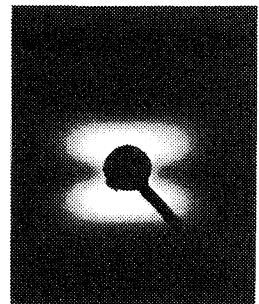

$\lambda 3.5 \quad T_{\mathrm{d}} 120^{\circ} \mathrm{C}$

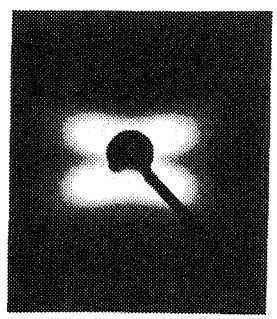

$3.5130^{\circ} \mathrm{C}$

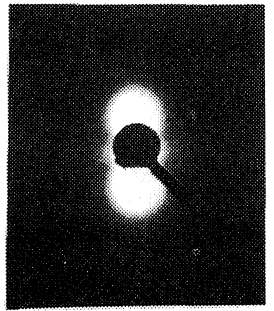

$9.3 \quad 150^{\circ} \mathrm{C}$

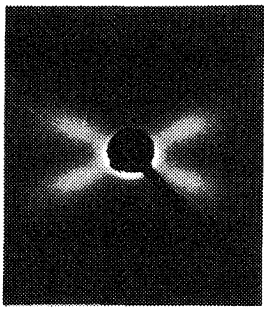

$7.4 \quad 120^{\circ} \mathrm{C}$

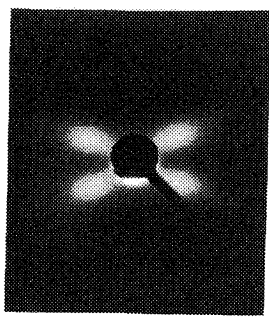

$5130^{\circ} \mathrm{C}$

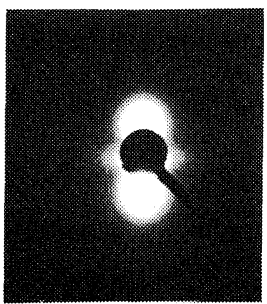

$17.9 \quad 150^{\circ} \mathrm{C}$
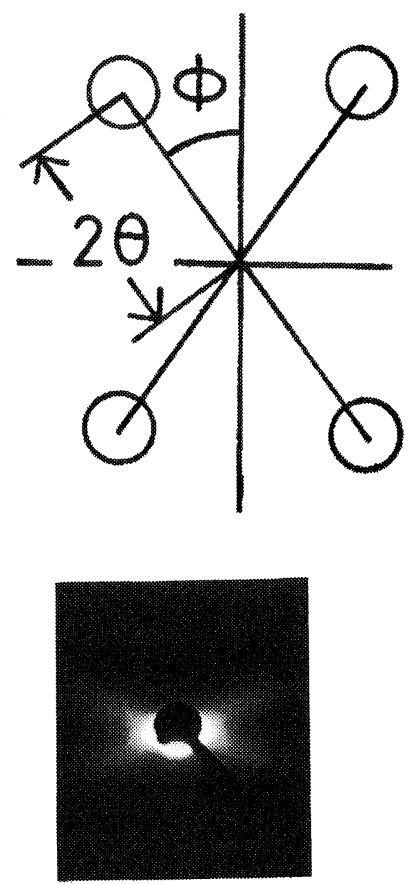

$11 \quad 130^{\circ} \mathrm{C}$

Figure 5. Small angle X-ray scattering patterns of $240 \mathrm{M}$ sheets. Drawing temperatures $\left(T_{\mathrm{d}}\right): 120^{\circ} \mathrm{C}$, $130^{\circ} \mathrm{C}, 150^{\circ} \mathrm{C}$; draw ratios $(\lambda), 3.5-17.9$; draw direction is vertical.

The SAXS photographs of the melt drawn sheets exhibited two intensity maxima on the meridian. The values of $L$ for these sheets were scarcely affected by draw ratio and drawing temperature (Table III).

Some of the highly drawn sheets showed only weak reflections.

\section{Melting Behavior}

The DSC curves of the $240 \mathrm{M}$ sheets are shown in Figure 6. It can be seen that for the solid drawn sheet, the melting peak shifts to high temperature and splits into two peaks with increasing draw ratio (Figure 6b). The increase in the melting temperature with the draw ratio may be due either to extension of the molecular chains, or to the strained amorphous region.

Sakami et al ${ }^{16-18}$ reported that a small amount of orthorhombic extended chain crystals having a high melting temperature of $150.5^{\circ} \mathrm{C}$ was produced by melt drawning of UHMW-PE. Our DSC curve of the mlet drawn sheet $(\lambda=9.3)$, exhibited a small 


\section{Hot Drawing of UHMW-PE}

melting peak at $150.9^{\circ} \mathrm{C}$ in addition to the main peak (Figure 6c). With increasing draw ratio, the endothermic area of the main peak decreased and a new melting peak appeared at about $140^{\circ} \mathrm{C}$ (Figure $6 d)$.

\section{Crystallinity}

The degrees of crystallinity of $145 \mathrm{M}$ and $240 \mathrm{M}$ sheets increased with the draw ratio, as shown in

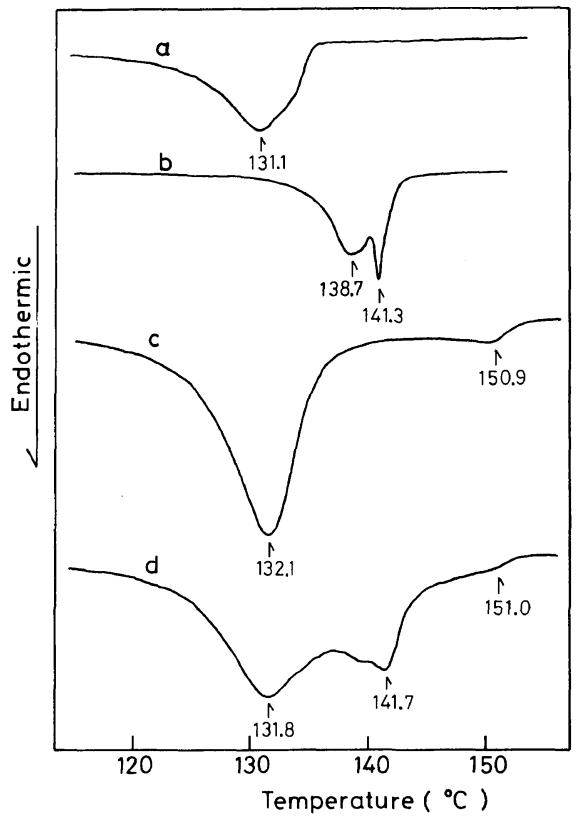

Figure 6. DSC curves for $240 \mathrm{M}$ sheets. (a) pristine sheet; (b) $T_{\mathrm{d}}=130^{\circ} \mathrm{C}, \lambda=11$; (c) $T_{\mathrm{d}}=150^{\circ} \mathrm{C}, \lambda=9.3$; (d) $T_{\mathrm{d}}=150^{\circ} \mathrm{C}, \lambda=17.9$.
Figure 7. The solid drawn $145 \mathrm{M}$ sheets had a higher degree of crystallinity than the solid drawn $240 \mathrm{M}$ sheets. At a fixed draw ratio, the degree of crystallinity of the melt drawn sheet decreased with an increase in the drawing temperature.

\section{DISCUSSION}

Effect of Molecular Weight on Maximum Draw Ratio and Optimum Drawing Temperature

As reported by Capaccio et al., 3,15 the maximum draw ratio obtained for a solid drawn UHMW-PE sheet was much lower than that for a hot drawn NMW-HDPE sheet. However, the UHMW-PE sheet can be melt drawn to a high extension. It is important to consider the presence of a superstructure network produced by entanglement of long molecular chains. ${ }^{28,29}$ Owing to the presence of such entanglements, the UHMW-PE sheet loses its fluidity and shows rubber-like elasticity in the melt. During the melt drawing, the entangled molecular chains tend to become aligned in the draw direction, which explains why the UHMW-PE sheet can be drawn in the melt.

On the basis of the classical theories of rubber elasticity, Smith et al. ${ }^{30}$ showed that the maximum draw ratio of polyethylene is as low as 3.7 , if the entanglements are completely trapped and made to act as permanent crosslinks during the drawing. Drawing to higher extension ratios requires chain disentanglement through slippage which should occur more easily at lower molecular weight. Therefore, the UHMW-PE sheet shows lower extensibility than the NMW-HDPE sheet in the solid

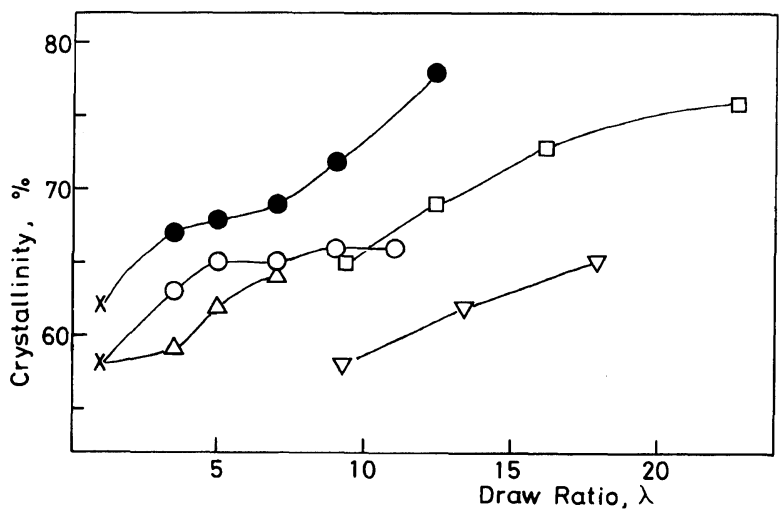

Figure 7. Crystallinity $v s$. draw ratio for $145 \mathrm{M}(\bigcirc)$ and $240 \mathrm{M}(\triangle, \bigcirc, \square, \nabla)$ sheets. Drawing temperatures: $120^{\circ} \mathrm{C}(\triangle) ; 130^{\circ} \mathrm{C}(\bigcirc, \bigcirc) ; 140^{\circ} \mathrm{C}(\square) ; 150^{\circ} \mathrm{C}(\nabla)$. 
state.

With increasing drawing temperature, the chain disentanglement is enhanced, but the increase in mobility of molecular chains causes partial randomization of the chain orientation (Figure 4). Therefore, the optimum drawing temperature is determined by a delicate balance between these two effects. Actually, the optimum drawing temperatures for the melt drawing of the $240 \mathrm{M}$ and $340 \mathrm{M}$ sheets were $136-140^{\circ} \mathrm{C}$ (Table II).

Although the $145 \mathrm{M}$ sheet could be drawn up to $\lambda=36$ at $136^{\circ} \mathrm{C}$, the resultant values of $f_{\mathrm{c}}=0.84$ and $f_{\mathrm{am}}=0.33$ were lower than those of the $240 \mathrm{M}$ sheet melt-drawn at $140^{\circ} \mathrm{C}$ (Figure 4). This may be attributed to a larger number of entanglements contained in UHMW-PE of higher molecular weight.

\section{Difference in Microstructure between Solid Drawn UHMW-PE and Solid Drawn NMW-HDPE Sheets}

The solid drawn UHMW-PE sheet showed a distinct difference in periodic structure from the hot drawn NMW-HDPE sheet. On drawing a NMWHDPE sheet, the lamellae may break up into blocks which subsequently aggregate to form a fibrillar structure consisting of alternating crystalline and amorphous layers. ${ }^{31,32}$ This is why the hot drawn NMW-HDPE sheet exhibited a two-point SAXS pattern. $^{31-33}$

A tilted four-point pattern was observed for the solid drawn UHMW-PE sheet. Tsvankin et al. ${ }^{34}$ studied various types of SAXS patterns. The tilted four-point pattern may be attributed to a stacking of inclined periodic layers. The periodic layer is formed by the arrangement of crystallites with the molecular chains parallel to the draw direction. On drawing, the inclination angle $\phi$ of the periodic layers increases by intercrystallite slippage in the chain direction and/or the shearing deformation of the crystallites.

The DSC melting behavior of the solid drawn UHMW-PE sheet also differs from that of the NMW-HDPE sheet. For the highly drawn NMWHDPE sheet, a sharp peak found at a high melting temperature was associated with the high degree of continuity of the crystalline matrix. ${ }^{35}$ On the other hand, the solid drawn UHMW-PE sheet showed two broad melting peaks at about $140^{\circ} \mathrm{C}$ (Figure $6 \mathrm{~b}$ ), suggesting a wide and bimodal distribution of crystal thickness. Characteristics of the solid drawn UHMW-PE sheet in the periodic structure and the melting behavior may be attributed to the presence of the superstructure network formed by chain entanglements, ${ }^{28}$ a large number of amorphous tie molecules, ${ }^{36}$ and the original spherulite structure. ${ }^{28}$

The undrawn UHMW-PE sheets had densities in the range $0.928-0.938$, and the degree of crystallinity was lower than that of the NMW-HDPE sheet. The degree of crystallinity of the hot drawn UHMW-PE sheets was also smaller than that of the hot drawn NMW-HDPE sheets. Among the three grades of UHMW-PE examined in this work, the solid drawn sheet of lower molecular weight UHMW-PE had a higher degree of crystallinity. The reason for this is that crystallization was restricted by entangled noncrystalline chains of high molecular weight.

\section{Crystalline Orientation and Microstructure of the Melt Drawn UHMW-PE Sheet}

Figure 8 shows the model of Keller et al. ${ }^{37,38}$ for the stress-induced crystallization of crosslinked polyethylene. The lamellae grow from the lineshaped nucleation centers aligned in the stress direction. At low stress, the crystals grow in the radial direction, forming lamellar crystals helically twisted as in normal spherulites and causing a random orientation of the a- and c-axes [texture (a) in Figure 8]. At high stress, the lamellae grow in a column with the c-axis parallel to the stress direction [texture (b) in Figure 8]. In both textures, the b-axis is oriented perpendicularly to the stress direction.

Since the network of UHMW-PE would crystallize under conditions of stress, the model of Keller $e t$ $a l$. is considered to be applicable to this case. The presence of textures (a) and (b) is consistent with the appearance of two components in the WAXD azimuthal scans of the (200) reflection (Figure 3), the highly oriented component arising from texture (b) and the almost randomly oriented component corresponding to texture (a).

The nucleation of crystals during the stress induced crystallization of crosslinked polyethylene was confirmed by the measurement of WAXD and observations by electron microscope. ${ }^{38}$ The DSC curves of the melt drawn UHMW-PE sheet exhibited a small melting peak at temperatures as high as $150-152^{\circ} \mathrm{C}$ (Figures $6 \mathrm{c}$ and $6 \mathrm{~d}$ ). It is likely that a few extended chain crystals are formed at the initial 


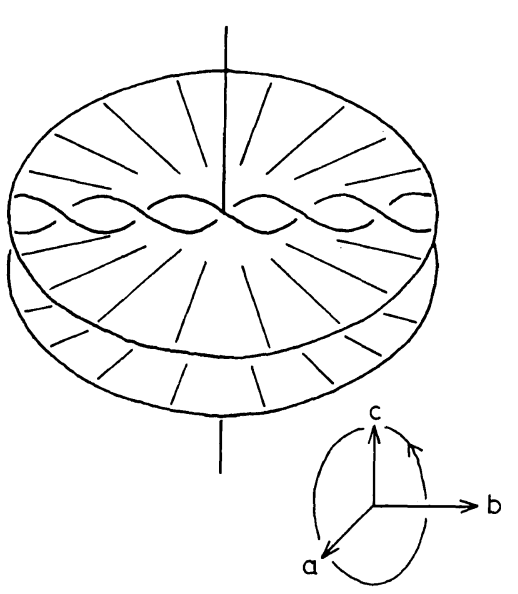

(a) Low stress

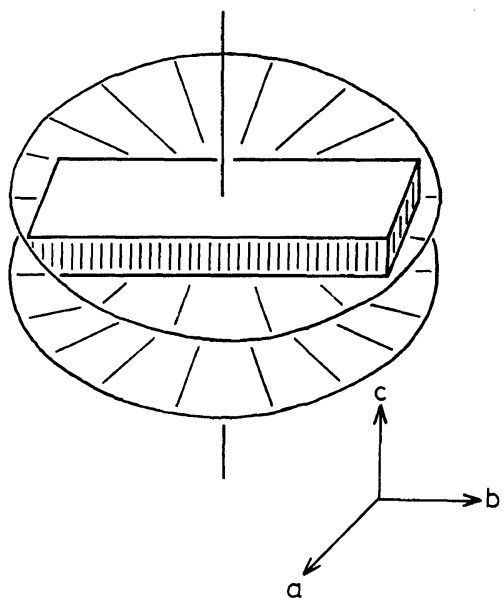

(b) High stress

Figure 8. Schematic diagrams of the Keller-Machin model ${ }^{38}$ for the crystallization of crosslinked polyethylene under (a) low stress and (b) high stress.

stage of stretching a melt of UHMW-PE and act as nucleation centers for crystallization to follow.

Crystal orientation and microstructure of the melt drawn sheet changed with the draw ratio. At higher draw ratios, the value of $f_{\mathrm{c}}$ increased (Figure 4) and a new melting peak appeared at about $140^{\circ} \mathrm{C}$ on the DSC curve (Figure 6d). These results suggest that texture (b) becomes predominant, the molecular chains are extended, and the amorphous region is strained as the draw ratio increases.

\section{Relationship between Young's Modulus and Micro- structure}

The degree of crystal orientation in the solid drawn sheet increased with increasing draw ratio, reaching a constant value beyond $\lambda=7$. Young's modulus continued to increase up to draw ratios above $\lambda=7$. Hence, the increase in Young's modulus may not be ascribable only to an increase in crystal orientation. According to the deformation mechanism proposed by Peterlin, ${ }^{39}$ amorphous taut tie molecules are formed in the intermicrofibrillar and intercrystallite regions by drawing and increase the density and orientation of the amorphous region. In the case of hot drawing, some of the tie molecules coalescence and crystallize into crystalline bridges. ${ }^{33}$ The formation of intercrystallite linkages displaces the DSC melting peak to the region of higher temperature and decreases the
SAXS intensity. ${ }^{7}$ Therefore, an increase in Young's modulus of the solid drawn sheet above $\lambda=7$ may be attributed mainly to an increase in the orientation of the amorphous region and the formation of intercrystallite linkages.

\section{CONCLUSION}

Since the superstructure network is formed by chain entanglements, the mechanical properties of UHMW-PE sheets can be improved not only by solid drawing but by melt drawing as well. In this case, melt drawing is more effective for higher molecular weight.

The improvement of mechanical properties by hot drawing is considered to be due to increasing chain orientation in the crystalline and amorphous regions and to the formation of intercrystallite linkages such as amorphous taut tie molecules and crystalline bridges.

Measurements of SAXS, DSC, and density show that solid drawn UHMW-PE sheets are different from hot drawn NMW-HDPE sheets with respect to periodic structure, melting behavior, and crystallinity.

Orientation in the crystalline region of melt drawn UHMW-PE sheets may be analyzed on the basis of the model of Keller et al..for stress-induced crystallization. The melt drawn UHMW-PE sheets 


\section{A. Kaito, K. Nakayama, and H. Kanetsuna}

consist of texture (a) with almost randomly oriented a- and c-axes and texture (b) with the c-axis highly oriented in the draw direction. With increasing draw ratio, the latter texture dominates over the former.

Acknowledgement. The authors wish to thank Dr. Yoji Maeda of the Research Institute for Polymers and Textiles for his valuable comments on DSC and density measurements.

\section{REFERENCES}

1. M. Takiura and M. Ishida, Plastics, 25-4, 77 (1974).

2. T. Shiraki, Plastics, 28-5, 57 (1977).

3. G. Capaccio, T. A. Crompton, and I. M. Ward, $J$. Polym. Sci., Polym. Phys. Ed., 14, 1641 (1976).

4. G. Capaccio, T. A. Crompton, and I. M. Ward, J. Polym. Sci., Polym. Phys. Ed., 18, 301 (1980).

5. L. Jarecki and D. J. Meier, Polymer, 20, 1078 (1979).

6. L. Jarecki and D. J. Meier, J. Polym. Sci., Polym. Phys. Ed., 17, 1611 (1979).

7. W. Wu, P. G. Simpson, and W. B. Black, J. Polym. Sci., Polym. Phys. Ed., 18, 751 (1980).

8. J. Smook, J. C. Torfs, P. F. van Hutten, and A. J. Pennings, Polym. Bull., 2, 293 (1980).

9. B. Kalb and A. J. Pennings, J. Mater. Sci., 15, 2584 (1980).

10. P. Smith and P. J. Lemstra, J. Mater. Sci., 15, 505 (1980).

11. P. Smith and P. J. Lemstra, Polymer, 21, 1341 (1980).

12. K. Nakayama and H. Kanetsuna, J. Jpn. Soc. Tech. Plast., 20, 229 (1979).

13. A. E. Zachariades, M. P. C. Watts, T. Kanamoto, and R. S. Porter, J. Polym. Sci., Polym. Lett. Ed., 17, 485 (1979).

14. A. E. Zachariades, M. P. C. Watts, and R. S. Porter, Polym. Eng. Sci., 20, 555 (1980).

15. G. Capaccio, T. A. Crompton, and I. M. Ward, Polymer, 17, 645 (1976).
16. H. Sakami, S. Iida, and K. Sasaki, Kobunshi Ronbunshu, 34, 653 (1977).

17. H. Sakami and T. Izushi, Kobunshi Ronbunshu, 36, 575 (1979).

18. H. Sakami, T. Izushi, and S. Iida, Kobunshi Ronbunshu, 38, 103 (1981).

19. P. Scherrer, Gött. Nachr., 2,98 (1918).

20. F. W. Jones, Proc. R. Soc., London, Ser. A, 116, 16 (1938).

21. P. H. Hermans, "Physics and Chemistry of Cellulose Fibers," Elesevier, Amsterdam, 1949.

22. P. R. Swan, J. Polym. Sci., 56, 403 (1962).

23. L. E. Nielson, J. Appl. Phys., 25, 1209 (1954).

24. M. G. Gubler and A. J. Kovacs, J. Polym. Sci., 34, 551 (1959).

25. R. S. Stein and F. H. Norris, J. Polym. Sci., 21, 381 (1956).

26. R. S. Stein, J. Polym. Sci., 34, 709 (1959).

27. K. Nakayama and H. Kanetsuna, J. Mater. Sci., 10, 1105 (1975).

28. J. Steidel and Z. Pelzbauer, J. Polym. Sci., C, 38, 345 (1972).

29. G. Capaccio and I. M. Ward, Polymer, 16, 239 (1975).

30. P. Smith, P. J. Lemstra, and H. C. Booij, J. Polym. Sci., Polym. Phys. Ed., 19, 877 (1981).

31. A. Peterlin, J. Polym. Sci., C, 15, 427 (1966).

32. A. Peterlin, J. Polym. Sci., C, 18, 123 (1967).

33. A. G. Gibson, D. R. Davies, and I. M. Ward, Polymer, 19, 683 (1979).

34. V. I. Gerasimov, Ya V. Genin, and D. Ya. Tsvankin, J. Polym. Sci., Polym. Phys. Ed., 12, 2035 (1974).

35. G. Capaccio, T. A. Crompton, and I. M. Ward, Polymer, 17, 644 (1976).

36. L. Mandelkern, J. Polym. Sci., C, 18, 51 (1976).

37. A. Keller and M. J. Machin, J. Macromol. Sci., B, 1, 41 (1967).

38. M. J. Hill and A. Keller, J. Macromol. Sci., B, 3, 153 (1969).

39. A. Peterlin, J. Polym. Sci., A-2, 7, 1151 (1969). 